Revue d'histoire de l'Amérique française

REVUE D.HISTOIRE DE L'AMÉRIQUE FRANÇAISE

\title{
LE TRESTE, Joseph, Souvenirs d'un missionnaire breton dans le Nord-Ouest canadien (Sillery, Le Septentrion, 1997), 332 p. Texte établi et commenté par Juliette Champagne.
}

\section{Gilles Lesage}

Volume 52, numéro 1, été 1998

URI : https://id.erudit.org/iderudit/005531ar

DOI : https://doi.org/10.7202/005531ar

Aller au sommaire du numéro

Éditeur(s)

Institut d'histoire de l'Amérique française

ISSN

0035-2357 (imprimé)

1492-1383 (numérique)

Découvrir la revue

Citer cet article

Lesage, G. (1998). LE TRESTE, Joseph, Souvenirs d'un missionnaire breton dans le Nord-Ouest canadien (Sillery, Le Septentrion, 1997), 332 p. Texte établi et commenté par Juliette Champagne. Revue d'histoire de l'Amérique française, 52(1), 111-112. https://doi.org/10.7202/005531ar d'utilisation que vous pouvez consulter en ligne.

https://apropos.erudit.org/fr/usagers/politique-dutilisation/ 


\section{NOTES BIBLIOGRAPHIQUES}

LE TRESTE, Joseph, Souvenirs d'un missionnaire breton dans le Nord-Ouest canadien (Sillery, Le Septentrion, 1997), 332 p. Texte établi et commenté par Juliette Champagne.

Publiée en collaboration avec la Western Canadian Publishers, cette édition d'un écrit de l'oblat Joseph Le Treste se situe, comme le signale Anne-Hélène Kerbiriou, dans la lignée des écrits autobiographiques oblats qu'a lancée $\mathrm{M}^{\mathrm{gr}}$ Taché en 1866 avec la publication de Vingt années de missions dans le Nord-Ouest de l'Amérique. En effet, d'autres «souvenirs» ont été publiés dans le passé, tels ceux de $\mathrm{M}^{\text {gr }}$ Émile Grouard et $\mathbf{M}^{\mathrm{gr}}$ Gabriel Breynat. Au texte lui-même, Juliette Champagne a ajouté une introduction de vingt-deux pages, de nombreuses notes infrapaginales (dont plusieurs citations de lettres de Joseph Le Treste), trois appendices (index géographique, itinéraire de vie de Joseph Le Treste et biographie) et une bibliographie. Le tout est illustré d'une série de photographies et de quelques cartes.

Joseph Le Treste est né à Bourgerel (Bretagne) en 1861. Après nous avoir fait part, en quelques pages, de son enfance, l'auteur, écrivant en 1944, nous raconte comment durant sa jeunesse il avait entendu $\mathrm{M}^{\mathrm{gr}}$ Isidore Clut et le père Auguste Lecorre faire état des missions de «l'extrême-nord du Canada». Ces témoignages le convainquirent de partir, en 1883, pour les missions du Nord-Ouest afin de «partager la vie dure et les travaux de ces gens si courageux» et «d'avoir la vie éternelle» (p. 63). Le lecteur suit les péripéties du missionnaire au Lac-la-Biche, où il a été ordonné prêtre, à Dunvegan, à Spirit River, à Grande Prairie, à Peace River, à Fort Vermilion, à Fort Chipewyan, à Fort McMurray et à Fort Smith.

Juliette Champagne nous apprend dans une note (p. 9) que le texte publié est tiré de la copie des archives des sœurs grises à Edmonton. Elle préfère toutefois donner la référence des Archives provinciales de l'Alberta où ont été déposées les archives des oblats de Marie-Immaculée, Province d'Alberta-Saskatchewan. Ces Souvenirs ont déjà fait l'objet d'une publication dans le Courrier de famille, circulaire du vicariat du Mackenzie. Dans son introduction, Juliette Champagne nous présente l'origine et l'histoire du texte, son genre et les particularités d'écriture du père Le Treste, le situant dans le contexte de son temps. Le Treste cherchait à éviter l'hagiographie souscrivant à l'écrit qui «s'en tient aux faits et n'invente pas» (p. 19). Trop peu de textes originaux des missionnaires oblats du Nord et de l'Ouest canadien sont disponibles dans des publications récentes. Cette édition commence, espérons-le, une nouvelle tradition. 